\title{
Use of semiochemicals for surveillance and control of hematophagous insects
}

\author{
Collins K. Mweresa ${ }^{1,2,4} \cdot$ W. R. Mukabana ${ }^{2,3} \cdot$ J. J. A. van Loon ${ }^{4} \cdot$ M. Dicke ${ }^{4}$ W. Takken ${ }^{4}$
}

Received: 3 October 2019 / Accepted: 16 June 2020 / Published online: 23 June 2020

(c) The Author(s) 2020

\begin{abstract}
Reliance on broad-spectrum insecticides and chemotherapeutic agents to control hematophagous insect vectors, and their related diseases is threatened by increasing insecticide and drug resistance, respectively. Thus, development of novel, alternative, complementary and effective technologies for surveillance and control of such insects is strongly encouraged. Semiochemicals are increasingly developed for monitoring and intervention of insect crop pests, but this has not been adequately addressed for hematophagous insects of medical and veterinary importance. This review provides an insight in the application of semiochemicals for control of hematophagous insects. Here, we provide specific information regarding the isolation and identification of semiochemical compounds, optimization approaches, detection, perception and discrimination by the insect olfactory system. Navigation of insects along wind-borne odor plumes is discussed and methods of odor application in field situations are reviewed. Finally, we discuss prospects and future challenges for the application of semiochemicalbased tools with emphasis on mosquitoes. The acquired knowledge can guide development of more effective components of integrated vector management, safeguard against emerging resistance of insects to existing insecticides and reduce the burden of vector-borne diseases.
\end{abstract}

Keywords Semiochemicals $\cdot$ Kairomones $\cdot$ Behavior $\cdot$ Monitoring $\cdot$ Attraction $\cdot$ Repellence $\cdot$ Flies $\cdot$ Mosquitoes

\section{Introduction}

Hematophagous insects bite, suck blood and transmit human as well as animal diseases (Logan and Birkett 2007; Valenzuela and Aksoy 2018; Barker and Reisen 2019). This threatens the achievement of the Sustainable Development Goals on poverty, hunger and disease eradication.

Communicated by Marko Rohlfs.

Collins K. Mweresa

collins.mweresa@yahoo.com

1 School of Biological and Physical Sciences, Jaramogi Oginga Odinga University of Science and Technology, P.O. Box 210-40601, Bondo, Kenya

2 Science for Health Society, P.O. Box 44970-00100, Nairobi, Kenya

3 School of Biological Sciences, University of Nairobi, P.O. Box 30197-00100, Nairobi, Kenya

4 Laboratory of Entomology, Wageningen University and Research, PO Box 16, 6700 AA Wageningen, The Netherlands
Traditional management of hematophagous insects and associated diseases has largely relied on the use of broad-spectrum insecticides and chemotherapy, respectively (WHO 2018). However, the use of insecticides against insect vectors is limited by increasing damage on the environment and non-target organisms, climate change, insecticide resistance and resurgence of insect vector populations (Ogden 2017; Onah et al. 2017). Thus, novel alternative complementary tools, technologies and approaches are urgently needed to control insect vectors (WHO 2018). A wide range of biological strategies including semiochemical-based technologies have been explored and exploited successfully for detection, monitoring and control of harmful insects, especially crop pests and tsetse flies (Cook et al. 2007; Logan et al. 2010; Brugman et al. 2018).

Semiochemicals are organic compounds that act as signals and enable intra- and inter-specific chemical communication (Nordlund and Lewis 1976; Dicke and Sabelis 1988; Landolt and Phillips 1997). The information conveyed is used for modulating physiological and behavioral activities through the olfactory and taste system (Dicke and Sabelis 1988; El-Shafie and Faleiro 2017) (Table 1). The chemicals 
Table 1 Definitions of common semiochemical terminologies (Dicke and Sabelis 1988; Landolt and Phillips 1997; El-Shafie and Faleiro 2017)

\begin{tabular}{ll}
\hline Terminology & Definition \\
\hline $\begin{array}{l}\text { Hematophagous insects } \\
\text { Semiochemical }\end{array}$ & $\begin{array}{l}\text { Insects that suck vertebrate blood and this action may transmit diseases or cause distress/harm in the host } \\
\text { Semiochemicals are organic compounds that act as signals and enable intra- and inter-specific chemical communica- } \\
\text { tion } \\
\text { Semiochemical that mediates an interaction between organisms of the same species }\end{array}$ \\
$\begin{array}{l}\text { Allelochemical } \\
\text { Kairomone }\end{array}$ & $\begin{array}{l}\text { Semiochemical that mediates an interaction between two individuals of different species } \\
\text { Allomone }\end{array}$ \\
$\begin{array}{l}\text { Synomone } \\
\text { An allelochemical that evokes a behavioral or physiological response that benefits the receiver but not the emitter }\end{array}$ \\
Apneumones
\end{tabular}

evoke stimulatory, inhibitory or deterrent behaviors in target organisms (El-Sayed 2015; El-Shafie and Faleiro 2017). Synthetic semiochemicals are increasingly being evaluated and manipulated to reduce transmission of vector-borne disease by disrupting mating, host-seeking, sugar-feeding, oviposition and interactions with natural enemies (Logan and Birkett 2007; El-Shafie and Faleiro 2017; Watentena and Okoye 2019). Semiochemical cues are used for a new generation of tools for integrated vector management and reduction of vector-borne diseases because they (1) are biologically active at very low concentrations, (2) mediate communication over relatively long distances compared to other means of communication in insects, (3) are specific and selective in action, especially pheromones, thus can be used to detect low insect numbers, (4) have not been associated with resistance or toxicity to non-target organisms and the environment compared to insecticides, (5) can be used indoors and outdoors to target feeding and resting habits of insect vectors and (6) can affect one or both sexes depending on the physiological state (Kline 2007; Mweresa et al. 2016; Maia et al. 2018; Nyasembe et al. 2019).

The history of tsetse control in some regions of Africa remains the most successful example of applying semiochemicals to control hematophagous insects (Vale and Torr 2004; Hassanali et al. 2008). Since then, numerous studies have been used to assess the effectiveness of deploying similar technologies to detect, monitor and control insect vectors of medical and veterinary importance through mating disruption, mass trapping, attract-and-kill, and push-pull techniques (Brugman et al. 2018; Watentena and Okoye 2019). Recent knowledge on insect olfactory system, behavior and genomics have also enhanced the potential of applying odor-baited technologies and approaches to control mosquito vectors. However, this is limited to small scale field trials (Mmbando et al. 2019; Nyasembe et al. 2019). Mass deployment of odor-baited traps to reduce malaria mosquitoes and malaria prevalence in western Kenya is a spectacular proof of concept regarding the effective integration of semiochemicals for trapping of host-seeking mosquito vectors (Homan et al. 2016) (Fig. 1). Many valuable lessons were learned thereby presenting a starting point for fine-tuning and replication of similar studies in other parts of the world. Here, current knowledge on the application of semiochemicals as a novel component for integrated vector management is reviewed. New approaches for detection, perception and discrimination of odor cues by the insect olfactory system and navigation of insects along wind-borne odor plumes are discussed, as well as methods of odor application in field situations. Future prospects and challenges for semiochemical-based tools are discussed, with emphasis on mosquito monitoring and control.

\section{Classification of Semiochemicals}

Semiochemicals that mediate responses in organisms of the same species are called pheromones; whereas, those that modulate communication between different species are termed allelochemicals (Nordlund and Lewis 1976; Dicke and Sabelis 1988; El-Shafie and Faleiro 2017) (Table 1). Insect biology relies on pheromones for mating, foraging, aggregation, trailing, dispersion, alarm, territoriality and oviposition behavior (Navarro-Silva et al. 2009; Stökl and Steiger 2017; Watentena and Okoye 2019). Pheromones are also subdivided into primer and releaser pheromones based on longevity of their behavioral responses. Primer pheromones trigger long-term physiological changes; while, releaser pheromones are associated with short-term or immediate behavioral responses (Dicke and Sabelis 1988; El-Shafie and Faleiro 2017). Most insect pheromones are believed to have originated from precursor compounds that were selected for information transfer or compounds which exploited pre-existing sensory components in the receiver (Stökl and Steiger 2017).

Allelochemicals that are adaptively favorable to the emitter but detrimental to the recipient are called allomones; 

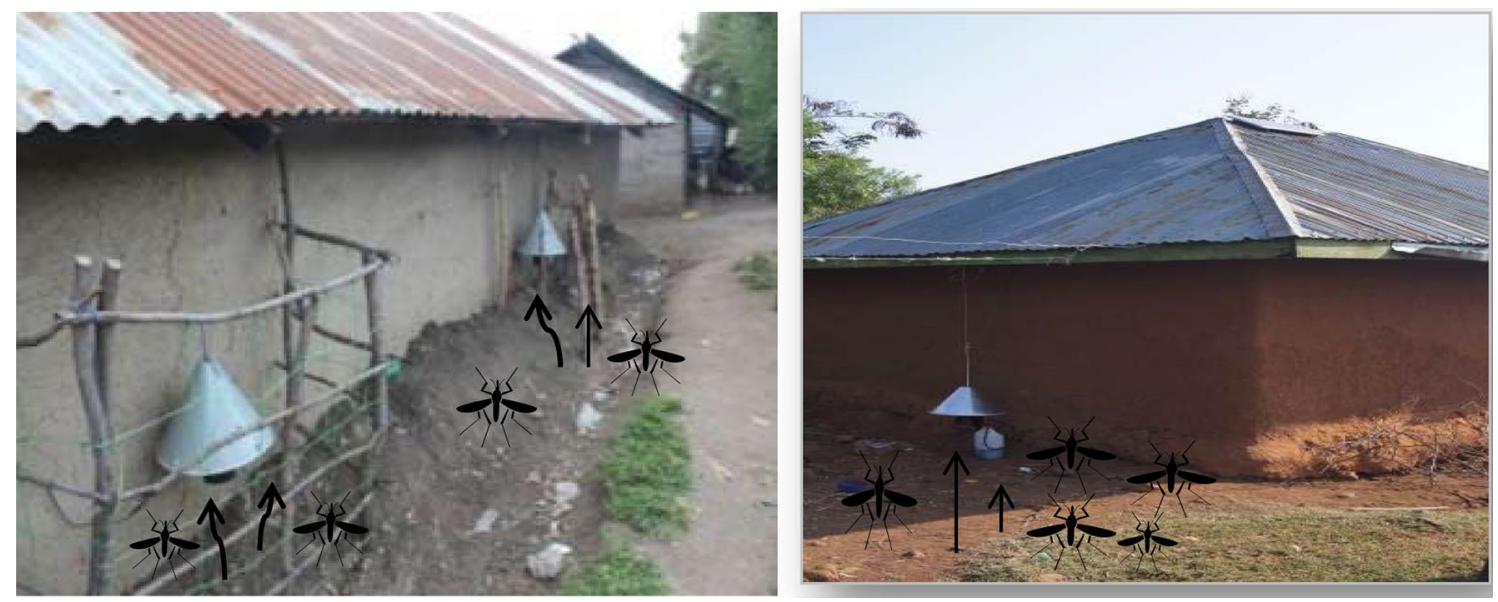

Fig. 1 Placement of solar-powered odor-baited traps for removal trapping of host-seeking mosquito vectors on Rusinga Island in Lake Victoria, western Kenya (Homan et al. 2016). The solar-powered traps were baited with synthetic odor blend and placed outdoors to

while, those that are beneficial to the receiving species are called kairomones (Dicke and Sabelis 1988; Fiorenzanoet al. 2017; Maia et al. 2018; Nyasembe et al. 2019). Semiochemicals with beneficial effects to the producer and receiver organism are termed synomones. For example, pollinating insects are attracted to scented floral structures; while, pest-infested plants may produce volatiles to attract natural enemies of the same pest in what is termed as "a cry for help" (Mcleod et al. 2005; Dudareva et al 2006; Dicke 2009; Hung et al. 2015). In addition, chemical volatiles emitted by non-living materials to stimulate physiologically and behaviorally beneficial responses to receiving organisms are called apneumones (Nordlund and Lewis 1976; Ong and Jaal 2015). Such responses may include the effect of nutrient composition on preferential selection of oviposition sites among insects (Navarro-Silva et al. 2009; Foti et al. 2016).

\section{Isolation, identification and optimization of semiochemicals}

Conventional and reverse chemical ecology approaches are mainly used to isolate, identify and optimize semiochemicals (Logan and Birkett 2007; Stökl and Steiger 2017; BarbosaCornelio et al. 2019). The conventional approach begins with collection of evidence on semiochemical-mediated interactions through laboratory and field behavioral experiments (Takken and Verhulst 2017). Active semiochemical components are extracted, identified and evaluated through a series of sensitive elaborate chemical, electrophysiological and behavioral analytical techniques (Yew and Chung 2015; El-Shafie and Faleiro 2017; Stökl and Steiger 2017). The components are collected and extracted from plant, insect intercept, and collect host-seeking mosquitoes before entering into human-occupied houses. The synthetic odorants in the blend were dispensed from nylon strips. Arrows illustrate flight direction of hostseeking mosquitoes towards the houses

or vertebrate sources by solvent washing, solid-phase microextraction (SPME), vacuum distillation and air entrainment (Logan et al 2010; Maksimovic et al. 2017; Barbosa-Cornelio et al. 2019).

Volatile components of interest are accurately quantified and identified by high-resolution gas chromatography (GC) and mass spectrometry (MS). Electrophysiologically active components derived from natural extracts are detected by electro-antennography and single sensillum recordings coupled with or without GC-MS (Qiu et al. 2004; Mcleod et al. 2005). The GC-MS technique is more suitable for analyzing low-molecular mass and mid- to low-polarity compounds (Pocsfalvi et al. 2016). This technique is rapidly and widely used to identify volatile organic compounds by comparing analyte mass spectra to those recorded in the databases with high efficiency (Tsizin et al. 2017). During electrophysiology, candidate components that stimulate olfactory receptors on the antennae and/or maxillary palps of insects are identified (Maksimovic et al. 2017). A signal recording obtained from an entire antenna is termed an electro-antennogram (EAG). Electrophysiologically active compounds are tested in behavioral experiments in conjunction with their authentic or synthetic analogs to ascertain whether they elicit similar responses in intact insects (Smallegange and Takken 2010). Behavioral experiments are first conducted under controlled laboratory conditions using olfactometers, wind tunnels, traps, large indoor cages, etc. Further investigations are performed in semi-field and field conditions to determine efficiency and optimal concentrations of candidate components (Smallegange and Takken 2010; Barbosa-Cornelio et al. 2019; Watentena and Okoye 2019). The compounds are released individually or in a mixture to determine whether 
they cause antagonistic and/or synergistic effects in target insects (Mweresa et al. 2016).

Field studies are essential because they provide data on efficiency of candidate cues, delivery systems, trap designs and placement before being deployed for monitoring and control of insect pests or vectors (Mukabana et al. 2010; Hiscox et al. 2014; Watentena and Okoye 2019). Natural semiochemicals are released in small quantities that may not be sufficient for different bioassays. Thus, adequate quantities are obtained through chemical synthesis where synthetic analogs are produced and used (Maksimovic et al. 2017). Recent advances in understanding of the molecular basis of insect olfaction have resulted in the adoption of a reverse chemical ecology approach for screening specific chemosensory proteins involved in the detection of semiochemicals (Barbosa-Cornelio et al. 2019). This approach is viewed as a modern technique towards identification of active volatile semiochemicals and has successfully been exploited for identification of an oviposition attractant of Culex quinquefasciatus (Choo et al. 2018).

\section{Detection and perception of semiochemicals by the insect olfactory system}

Insects have evolved a highly sensitive olfactory system to identify and discriminate a broad range of natural olfactory stimuli essential for survival and reproduction (Zwiebel and Takken 2011; Carey and Carlson 2011; Yang et al. 2019). This is why the olfactory system of insects is equipped with odorant receptors (ORs), ionotropic receptors (IRs) and sometimes gustatory receptors (GRs) housed in the dendritic membrane of olfactory receptor neurons (ORNs) (Andersson et al. 2015). Olfactory receptor neurons are primarily located in the sensilla (hair like extensions) of the antennae, maxillary palps, and even in the proboscis of some insects (Kay and Stopfer 2006; Benton 2009). The walls of olfactory sensilla are multiporous, and each sensilla houses two or more bipolar ORNs (Leal 2013). Activation of ORNs generates electrical activity that is relayed to the insect primary olfactory centers of the brain, the antennal lobes (Kay and Stopfer 2006; Benton 2009; Ray 2016; Yang et al. 2019). Each antennal lobe comprises synaptic units termed glomeruli, which occur in characteristic patterns of arrangement, shapes and sizes in different species. Olfactory information is transmitted from the glomeruli to higher brain orders in the protocerebrum for integration within and across modalities, thereby causing appropriate physiological and behavioral responses in the insect (Benton 2009; Reisenman et al. 2016; Yang et al. 2019). However, these processes are achieved through involvement of chemosensory proteins expressed in the antennae. In addition to ORs and IRs, the proteins include odorant-binding proteins (OBPs), chemosensory proteins (CSPs), pheromone binding proteins (PBPs), sensory neuron membrane proteins (SNMPs) and odorant-degrading enzymes (ODEs) (Sánchez-Gracia et al. 2009; Leal 2013). In Lepidoptera species, OBPs are divided into PBPs and general odorant-binding proteins (GOBPs) (Yang et al. 2019). The OBPs, PBPs and CSPs are highly abundant in the sensillar lymph of insect antennae (Benton 2009; Leal 2013). They bind to hydrophobic odorant molecules and transport them in a pH-dependent manner to ORs during the first step of olfactory detection (Fan et al. 2011; Leal 2013).

Upon reaching the olfactory organs, volatile chemical stimuli traverse through pores on the sensilla into the lymph and selectively bind and interact with different types of olfactory proteins including OBPs or PBPs for transport and attachment onto the dendrite of ORNs (Leal 2013; Andersson et al. 2015). It is known that odorants activate many ORCs, and that each ORC can be activated by different odorants (Wang et al. 2003). However, recent studies indicate that ecologically relevant odorants are detected by highly specific ORs and specified neural pathways as illustrated by Andersson et al. (2015). In both cases, the nature of responses observed is also dependent on the type of chemoreceptors expressed by the insect and types of features encoded to govern the pattern of activities in the glomerulus (Reisenman et al. 2016). Thus, candidate compounds that may alter odor processing could be useful in tapping the potential of manipulating semiochemical cues for surveillance and mass trapping of hematophagous insects (Watentena and Okoye 2019). Indeed, enhanced knowledge on how the olfactory system detects and processes semiochemicals has remarkably contributed to the design of efficient tools for monitoring and control of hematophagous insects that transmit diseases (Brugman et al. 2018).

\section{Discrimination of odor stimuli}

In insects, odors often activate independent pathways for processing pheromone and non-pheromone olfactory stimuli as an aspect of functional partitioning (Pelletier et al. 2010; Leal 2013; Ray 2016). This is enhanced by structural, functional and location differences of odor and pheromone binding proteins in the antennae and labial palps for selective detection and transport of stimuli. In general, odor stimuli are distinguished based on temporal and spatial patterns of glomerular activation (Pelletier et al. 2010). At the behavioral level, an intermittent flow of odor(s) initiates and sustains flight or walking upwind towards the source in many insects like moths, tsetse flies and mosquitoes (Murlis et al. 1992). The composition, concentration and ratio of components in synthetic and natural odor blends play a vital role during selective detection and behavioral responses of 
insects to semiochemicals (Grünbaum and Willis 2015; Riffell et al. 2009). At the neural level, selectivity depends on the length of the compound, position of double bonds, types and positions of functional groups on the compound (Galizia and Rössler 2010). Nevertheless, the speed of air flow and temporal dynamics of odor stimulation are equally important factors affecting odor representation (Grünbaum and Willis 2015). Consequently, knowledge about the dynamics involved in discrimination of semiochemical stimuli is important for selection and optimization of putative behaviorally active compounds (Reisenman et al. 2016; Watentena and Okoye 2019). Such compounds are likely to provide a potential for developing novel attractant or repellent blends for manipulation of selected insect species (Menger et al. 2016; Ray 2016; Kły’s et al. 2017).

\section{Navigation of insects in odor plumes}

Insects locate resources by detecting and relying on wind direction to navigate along wind-borne odor plumes towards the source (Murlis et al. 1992; Spitzen et al. 2013; Kły's et al. 2017). Although insects have to find odor sources, the rate at which the process is achieved depends on potential selective forces. The forces include economy of movement, urgency or survival value of the response, background odor, visual cues and likelihood of source location under prevailing ecological conditions (Grünbaum and Willis 2015; Reisenman et al. 2016). A detailed description of how odor is distributed within the plume, strategies for finding an odor plume, mechanisms of detecting wind flow, direction of wind flow as a directional guide to the odor source, and the kinds of orientation maneuvers used by insects in navigation was reviewed elsewhere (Cardé and Willis 2008; Cardé and Gibson 2010). Therefore, the insect has to maintain intermittent contact with the semiochemical plume. This because orientation and movement toward odor sources are also determined by the semiochemical identity and structure of the plume (Namiki and Kanzaki 2016; Liberzon et al. 2018). Such knowledge has enhanced our understanding on how hematophagous insects navigate towards semiochemical sources, optimal height and distances over which odor-baited tools may be effectively attractive or repellent to target insect species in the field (Homan et al. 2016; Menger et al. 2016; Mmbando et al. 2019). Recent studies have demonstrated flight dynamics of malaria mosquitoes around human dwellings, odor-baited traps, capture and escape dynamics (Spitzen et al. 2013; Cribellier et al. 2018). In mosquitoes and tsetse flies, interactions between visual, olfactory and environmental cues like temperature, relative humidity, wind direction and velocity are equally important. They can mask or enhance the way insects respond to semiochemicals (Grünbaum and Willis 2015; Liberzon et al.
2018). This understanding creates possibilities of combining multiple cues including olfactory, visual and environmental to design effective surveillance and control tools for many hematophagous insect vectors including mosquitoes (Mota et al. 2014; Hawkes et al 2017; Ryelandt et al. 2011).

\section{Methods of dispensing semiochemicals}

Behavioral manipulation of hematophagous insects requires that semiochemicals are released in a controlled form to mimic natural situations. This is achieved by selection of release devices that allow (1) sustained release of optimal concentrations of biologically active volatile organic compounds for eliciting desired responses and over intended period of time, (2) control of various release parameters, (3) considerable residual effect of odorants over a given period of time, (4) replication of elicited behavior by artificially created odor plumes, (5) protection of active ingredients from degradation by UV light, oxygen or reaction with dispensing devices because majority are chemically unstable, (6) convenience in terms of cost effectiveness and minimal environmental damage and (7) optimal effectiveness of dispensers to disrupt the behavior of insect pests and vectors (Torr et al. 1997; Baroffio et al. 2016; Watentena and Okoye 2019). The outcome effects are more profound when semiochemicals are applied at the start of the season because insect densities are usually low.

The most commonly used slow-release dispensers for behavioral manipulation of insect pests and vectors include solid matrices like polyethylene sachets, vials, beads, tubes and sticks, glass, rubber septa, rubber wicks, membranes, spiral polymer dispensers, polyvinyl chloride (PVC), gel-like dispenser matrix, wax formulation, polyamide nylon, cotton, polyester, cellulose and polyacrylate material (Heuskin et al. 2011; Mweresa et al. 2014a; Mmbando et al. 2019). In such cases, the actual amount of semiochemicals released in the atmosphere and active range is dependent on the choice of delivery matrices, changes in environmental parameters like atmospheric pressure, temperature, wind speed, relative humidity and the physical properties of the surroundings (Torr et al. 1997; Heuskin et al. 2011; Baroffio et al. 2016). Wind affects odor detection and location by disturbing and influencing structure of the odor plume to which insects respond (Cardé and Willis 2008; Cardé and Gibson 2010; Liberzon et al. 2018). Although solid dispensers are commonly applied for monitoring and control of harmful insects, they are limited in terms of sustaining optimal release rates and concentrations of active semiochemical components over prolonged periods and optimal distance.

Aerosol emitters consisting of electronically programmed reservoirs are used to release large quantities of pheromones by means of pressurized aerosol at fixed time intervals. This 
reduces the numbers of dispensers used in sustaining optimal rates of active components. Currently, inkjet dispensing technologies are being considered for release of semiochemicals and other materials in a drop-on-demand mode (Machekposhti et al. 2019). The system consists of a selfcontained reservoir attached to polythene tube or tygon silicon tubing through which semiochemicals diffuse. This type of system reduces wastage, repeated application and may be fitted with weather monitoring devices to allow correlation of environmental parameters with its efficiency.

\section{Approaches for application of semiochemical-based methods}

Semiochemicals can be applied to control insect pests and vectors through four basic methods depending on the goal and scope of activity (Kline 2007; Heuskin et al. 2011; ElShafie and Faleiro 2017). The methods include mass trapping, mating disruption, lure and kill, as well as push-pull. In mass trapping, large numbers of target populations are lured by use of visual, auditory and/or attractant cues into focal areas, and then killed (Ong and Jaal 2015; Homan et al. 2016; Watentena and Okoye 2019) (Fig. 1). This method is viewed as an alternative to area-wide application of insecticides and is more effective against low population densities, or when initiated at the start of the season. However, it is expensive in terms of traps, deployment and sustainability (Vale and Torr 2004; Kline 2007). Unlike odor-baited traps, targets often comprise a combination of olfactory and visual cues.

Mating disruption involves interfering with mate searching behavior of males by using pheromones so that females remain virgins (Cardé and Minks 1995; Miller and Gut 2015). This type of method can either be non-competitive or competitive (Miller and Gut 2015). Non-competitive methods prevent pheromone emission and interfere with sensory responses in male or female insects. Competitive methods include attraction or false trail following, camouflage due to complete saturation of the environment with a synthetic pheromone that prevents males from locating the females. It also involves desensitization and sensory imbalance due to overexposure of male olfactory receptor system to synthetic pheromones (El-Shafie and Faleiro 2017). The success of mating disruption depends on population density, magnitude of isolation of the target area, mating behavior, optimal release rates, active period of the insect and pheromone concentrations to which males respond. A review by Reisenman et al. (2016) indicates that pheromones can mediate mating disruption through the following mechanisms (1) loss of sensitivity in odor receptor cells (sensory adaptation), (2) loss of sensitivity in the central nervous system (habituation), (3) camouflaging of the female's odor trail, (4) competition between dispensers and natural pheromone and (5) imbalance in the constituents of synthetic pheromones. Currently, new techniques are being developed to improve efficacy of this approach particularly for the control of insect plant pests. For instance, auto-confusion disruption technique is being explored to impair orientation of male moths towards natural sources of pheromones (Huang et al. 2010; Miller and Gut 2015).

Lure and kill is the utilization of attractants to bring large numbers of target insects into contact with toxic, sterilizing, or pathogenic agents impregnated on a resting surface or in a trap. This serves as an important method of reducing the impact of insecticides on non-target organisms (Day and Sjogren 1994; Homan et al. 2016). Both mass trapping and lure-and-kill approaches have been reported for screwworm flies, Cochliomyia hominivorax and $C$. macellaria, tsetse flies, and on a limited spatial and temporal scale for mosquitoes (Cook et al. 2007; El-Sayed 2015; Homan et al. 2016).

Repellents and attractants can also be integrated in a push-pull strategy to direct movement and manage hematophagous dipterans like tsetse flies, mosquitoes and sand flies (Vale and Torr 2004; Menger et al. 2016; Mmbando et al. 2019). The target insect is repelled or pushed away from a protected resource and lured or pulled to an alternative source for removal. Attractant cues may include aggregation pheromones, sex pheromones, host volatiles, and oviposition or gustatory stimulants. Repellents, deterrents or inhibitors may comprise of non-aggregation and alarm pheromones or non-host or non-oviposition volatiles (Ong and Jaal 2015; El-Shafie and Faleiro 2017; Stökl and Steiger 2017). Repellents prevent insects from reaching a target resource to which they would have otherwise been attracted by causing avoidance behavior. Whereas topical repellents are applied onto the skin to provide individual protection, spatial repellents vaporize into the air. This creates a vector-free space for protection of multiple individuals against arthropod bites especially insect vectors and crop pests (Reisenman et al. 2016).

Several semiochemicals with repellent effects are currently available but their practical applications are limited by availability of cheaper and effective pest control alternatives, lack of adequate formulations and regulatory obstacles including registration (Isman 2006). Insect repellents are mainly derived from natural sources including plants and animals. However, N,N-diethyl-3-methylbenzamide, also known as DEET, remains the world's most widely used topical insect repellent (Leal 2014; Watentena and Okoye 2019). Importantly, various investigations have focused in determining the molecular mechanism of action 
of this repellent (Ditzen et al. 2008; Syed et al. 2011; DeGennaro et al. 2013; Xu et al. 2014).

\section{Placement of semiochemical-based tools}

Effective deployment of semiochemical-based tools for surveillance and control of hematophagous insects depends on in-depth understanding of sugar-feeding, mating, host-seeking and oviposition or larviposition behavior (Baroffio et al. 2016; Brugman et al. 2018). This understanding contributes to decision-making on optimal placement, density, color and designs of traps/targets needed for effective monitoring of insect pest populations and protection of host or target resources (Kline 2006, 2007; Sumaye et al. 2012; Watentena and Okoye 2019) (Fig. 1). Strategic placement can be achieved by (1) formation of a perimeter barrier around an area of protection with a highly aggregated population that is surrounded by potential habitats of hematophagous insects (Kline and Lemire 1998; Mweresa et al. 2016), (2) deployment of individual traps and targets within a protection area that has few but identifiable hot spots of vectors (Homan et al. 2016) and (3) intercepting vectors during dispersal from breeding sites or resting sites surrounded by potential hosts (Kline and Lemire 1998; El-Sayed et al. 2006; El-Shafie and Faleiro 2017) (Fig. 1).

Currently, successful deployment of semiochemicalbaited trapping technologies in disease-endemic areas is enhanced by the discovery of (1) more potent synthetic attractant formulations or improvement of existing ones (Smallegange et al. 2005; Mweresa et al. 2016), (2) novel spatial repellents (Menger et al. 2016), (3) more effective and long-lasting slow-release systems for odorants (Mweresa et al. 2014a, 2015), (4) efficient trapping devices that rely on cheap or renewable sources of energy including solar-powered traps (Kline 2006; Hiscox et al. 2014; Homan et al. 2016) (Fig. 1) and (5) alternative sources and more effective methods of delivering carbon dioxide and other volatile kairomones (Mukabana et al. 2010; Smallegange and Takken 2010; Mweresa et al. 2014b). Recent advances in the manipulation of semiochemicals for surveillance and control of major insect vectors of diseases have been reviewed elsewhere (Brugman et al. 2018; Watentena and Okoye 2019). The vectors include tsetse flies, mosquitoes, biting midges, sand flies, black flies, horse flies, horn flies and stable flies. Most of the progress made is based on effective application of sugarfeeding, host-seeking and oviposition cues (Homan et al. 2016; Fiorenzano et al. 2017; Watentena and Okoye 2019).

\section{Prospects and future challenges}

Semiochemical-based technologies are currently developed as promising methods for detection, surveillance and control of hematophagous insects of public health and livestock importance. This is achieved through behavioral manipulation of target insects using synthetic versions of natural volatile and non-volatile semiochemical cues to initiate intra- and or inter-specific communication between organisms. The manipulation causes attraction, deterrent or repellence behavior of insects. Semiochemicals are deployed as trap and or target baits, dispensed as repellents or integrated with attractants in a push-pull system. Resistance of insects to semiochemicals has not been reported possibly because they are natural cues to which insects respond for survival. This review focuses on current knowledge and identifies gaps that should be bridged to enhance the application of semiochemicals as a novel alternative technology for monitoring and controlling hematophagous insects.

New discoveries in the insect olfactory system, behavior, genetics, and genomics over the last two decades have enhanced the application of odor-baited technologies and approaches for management of harmful hematophagous insects especially mosquito vectors. The molecular basis of insect responses to semiochemicals has been unravelled and shown how the olfactory systems of insects detect and process olfactory cues. Advanced approach for screening chemosensory proteins involved in the detection of important volatile semiochemicals has also contributed to adoption of reverse chemical ecology techniques. Although various natural bio-active semiochemical blends have been identified, their chemical composition, combination ratios, optimal concentrations, interactive effects and release rates are not fully understood. Similarly, mechanisms underlying molecular interaction with olfactory proteins and coding ratios of active constituents especially in the higher brain of blood-sucking insects should be investigated further to fully understand how semiochemicals can be used for controlling behavior. Hematophagous insects are guided towards or away from different semiochemical sources by navigating a long wind-borne odor plume of cues acting at a close, medium or long range. Recent findings on flight dynamics of malaria mosquitoes around human dwellings, odor-baited traps, capture and escape patterns has remarkably influenced application of semiochemical-based technologies for monitoring and control of insect vectors (Cribellier et al. 2018). However, similar information is urgently needed for other insect vectors including other mosquito vectors, biting midges, tsetse flies, myiasis-causing flies, sand flies, black flies and triatomine bugs (Brugman et al. 2018). Insects also 
respond to interactive effects of olfactory, auditory, visual and physical cues. Although this has been widely used to design effective tsetse fly traps and targets, combined effect of deploying such cues should be explored further especially in major mosquito vectors.

The majority of traps and targets baited with mating, oviposition and host-seeking odors are selectively biased for collection of female insect vectors making it difficult to target male, blood-fed, gravid and infected female individuals of the same species. Pheromones are mainly manipulated for behavioral disruption of insect crop pests and less for hematophagous insect vectors. This partly explains why pheromones have significantly contributed to the success of deploying semiochemical-based technologies to manage insect crop pests. However, similar techniques should also be explored for the surveillance and control of insect vectors including mosquitoes.

The push-pull approach has been successful for controlling hematophagous insects like tsetse flies, horse flies and mosquitoes. Nevertheless, highly potent long-lasting baits, spatial repellents, appropriate odor dispensers and trap designs that rely on cost-effective sources of energy are needed. Currently, inkjet dispensing technologies are being considered for the release of semiochemicals and other materials in a drop-on-demand mode. This technology reduces wastage, repeated application of semiochemicals and may be fitted with weather monitoring devices to allow correlation of environmental parameters with its efficiency. The parameters include atmospheric pressure, temperature, wind speed, relative humidity and the physical properties of the surrounding. As a result, further semi-field and field experiments are required in areas where vectors and their disease-causing pathogens are normally found.

Area-wide deployment is strongly encouraged for impact assesment of the technology on disease prevalence and incidence in endemic areas of the world but this is confounded with several challenges (Maia et al. 2018; Sternberg and Thomas 2018). This requires commitment from all stakeholders, more multidisciplinary studies on emerging dynamics of human insect vector behavior and interactions, specialized novel equipments and facilities. Facilities like large screened cages, some of which may contain in-built experimental huts as well as infrastructure, appropriate expertise and funding are also essential. Such requirements are often absent in most parts of the world where vector-borne diseases have remained a hindrance to socio-economic growth. However, recent use of simple odor-baited devices for surveillance and control of tsetse flies and mosquitoes has shown that the technology can also be exploited in resourcepoor rural areas of sub-Saharan Africa (Vale and Torr 2004; Hassanali et al. 2008; Homan et al. 2016). It is for these reasons that multidisciplinary studies are needed for further improvement and application of semiochemical-based technologies within integrated vector management frameworks. These will reduce over reliance on insecticides, burden of vector-borne diseases and stimulate socio-economic development.

Acknowledgements This research was funded by a grant from the Foundation for the National Institutes of Health (FNIH) through the Grand Challenges in Global Health initiative (GCGH \#121) and a sandwich Ph.D. scholarship of Wageningen University and Research, The Netherlands (CKM). CKM was hosted by ICIPE-TRO campus as a Dissertation Research Internship Program (DRIP) scholar and is currently employed at Jaramogi Oginga Odinga University of Science and Technology, Kenya (JOOUST). We thank an anonymous reviewer for the useful comments that have strengthened the manuscript.

\section{Compliance with ethical standards}

Conflict of interest The authors are not aware of any affiliations, memberships, funding, or financial holdings that might be perceived as affecting the objectivity of this review.

Open Access This article is licensed under a Creative Commons Attribution 4.0 International License, which permits use, sharing, adaptation, distribution and reproduction in any medium or format, as long as you give appropriate credit to the original author(s) and the source, provide a link to the Creative Commons licence, and indicate if changes were made. The images or other third party material in this article are included in the article's Creative Commons licence, unless indicated otherwise in a credit line to the material. If material is not included in the article's Creative Commons licence and your intended use is not permitted by statutory regulation or exceeds the permitted use, you will need to obtain permission directly from the copyright holder. To view a copy of this licence, visit http://creativecommons.org/licenses/by/4.0/.

\section{References}

Andersson MN, Löfstedt C, Newcomb RD (2015) Insect olfaction and the evolution of receptor tuning. Front Ecol Evol 3:53

Barbosa-Cornelio R, Cantor F, Coy-Barrera E, Rodríguez D (2019) Tools in the investigation of volatile semiochemicals on insects: from sampling to statistical analysis. Insects 10:241

Barker CM, Reisen WK (2019) Epidemiology of vector-borne diseases. Med Vet Entomol 3(4):33-49

Baroffio A, Guibert V, Richoz P et al (2016) Management of insect pests using semiochemical traps. Acta Hortic 1137:17

Benton R (2009) Molecular basis of odor detection in insects. Ann N Y Acad Sci 1170:478-481

Brugman VA, Smallegange RC, Logan JG (2018) Semiochemical tools for a new generation of livestock pest control. Ecol Control Vector-borne Dis 5:389-434

Cardé R, Gibson G (2010) Host finding by female mosquitoes: mechanisms of orientation to host odors and other cues. In: Takken W, Knols BGJ (eds) Olfaction in vector-host interactions, vol 6. Wageningen Academic Publishers, The Netherlands, pp 115-141

Cardé RT, Minks AK (1995) Control of moth pests by mating disruption: successes and constraints. Annu Rev Entomol 40:559-585

Cardé RT, Willis M (2008) Navigational strategies used by insects to find distant, wind-borne sources of odor. J Chem Ecol 34:854-866

Carey AF, Carlson JR (2011) Insect olfaction from model systems to disease control. Proc Natl Acad Sci 108(32):12987-12995 
Choo YM, Xu P, Hwang JK et al (2018) Reverse chemical ecology approach for the identification of an oviposition attractant for Culex quinquefasciatus. Proc Natl Acad Sci 115:714-719

Cook MS, Khan ZR, Pickett JA (2007) The use of push-pull strategies in integrated pest management. Annu Rev Entomol 52:375-400

Cribellier A, Erp JA, Hiscox A et al (2018) Flight dynamics of malaria mosquitoes around odor-baited traps: capture and escape dynamics. R Soc Open Sci 5:180246

Day J, Sjogren R (1994) Vector control by removal trapping. Am J Trop Med Hyg 50:126-133

DeGennaro M, McBride CS, Seeholzer L, Nakagawa T, Dennis EJ, Goldman C, Jasinskiene N, James AA, Vosshall LB (2013) Orco mutant mosquitoes lose strong preference for humans and are not repelled by volatile DEET. Nature 498(7455):487-491. https:// doi.org/10.1038/nature12206

Dicke M (2009) Behavioral and community ecology of plants that cry for help. Cell Environ 32:654-665

Dicke M, Sabelis MW (1988) Infochemical terminology: based on cost-benefit analysis rather than origin of compounds. Funct Ecol 2:131-213

Ditzen M, Pellegrino M, Vosshall LB (2008) Insect odorant receptors are molecular targets of the insect repellent DEET. Science 319:1838-1842

Dudareva N, Negre F, Nagegowda DA, Orlova I (2006) Plant volatiles: recent advances and future perspectives. Crit Rev Plant Sci 25:417-440

El-Sayed AM (2015) The pherobase: database of insect pheromones and semiochemicals. https://www.pherobase.com. Accessed Mar 2018

El-Sayed AM, Suckling D, Wearing C, Byers J (2006) Potential of mass trapping for long-term pest management and eradication of invasive species. J Econ Entomol 99:1550-1564

El-Shafie HAF, Faleiro JR (2017) Semiochemicals and their potential use in pest management. Biol Control Pest Vector Insects. https ://doi.org/10.5772/66463

Fan J, Francis F, Liu Y, Chen JL, Cheng DF (2011) An overview of odorant-binding protein functions in insect peripheral olfactory reception. GMR 10:3056-3069

Fiorenzano JM, Koehler PG, Xue R (2017) Attractive toxic sugar bait (ATSB) for control of mosquitoes and its impact on non-target organisms: a review. Int J Environ Res 14(4):398

Foti MC, Rostás M, Peri E et al (2016) Chemical ecology meets conservation biological control: identifying plant volatiles as predictors of floral resource suitability for an egg parasitoid of stink bugs. J Pest Sci 90:299-310

Galizia CG, Rössler W (2010) Parallel olfactory systems in insects: anatomy and function. Annu Rev Entomol 55:399-420

Grünbaum D, Willis MA (2015) Spatial memory-based behaviors for locating sources of odor plumes. Mov Ecol 3:11

Hassanali A, Herren H, Khan ZA, Pickett JA, Woodcock CM (2008) Integrated pest management: the push-pull approach for controlling insect pests and weeds of cereals, and its potential for other agricultural systems including animal husbandry. Phil Trans R Soc 363:611-621

Hawkes FM, Dabire RK, Sawadogo SP, Torr SJ, Gibson G (2017) Exploiting Anopheles responses to thermal, odour and visual stimuli to improve surveillance and control of malaria. Sci Rep $7: 17283$

Heuskin S, Verheggen FJ, Haubruge E, Wathelet J, Lognay G (2011) The use of semiochemical slow-release devices in integrated pest management strategies. Biotechnol Agron Soc Environ $15: 459-470$

Hiscox A, Otieno B, Kibet A et al (2014) Development and optimization of the Suna trap as a tool for mosquito monitoring and control. Malar J 13:257
Homan T, Hiscox A, Mweresa CK et al (2016) The effect of mass mosquito trapping on malaria transmission and disease burden (SolarMal): a stepped-wedge cluster randomized trial. Lancet 388:10050

Huang J, Stelinski LL, Gut LJ (2010) Mating behaviors of Cydia pomonella (Lepidoptera: Tortricidae) as influenced by sex pheromone in electrostatic powder. J Econ Entomol 103:2100-2106

Hung KY, Michailides TJ, Gerry AC (2015) House fly (Musca domestica L.) attraction to insect honeydew. PLoS ONE 10(5):e0124746

Isman MB (2006) Botanical insecticides, deterrents and repellents in modern agriculture and an increasingly regulated world. Annu Rev Entomol 51:45-66

Kay LM, Stopfer M (2006) Information processing in the olfactory systems of insects and vertebrates. Semin Cell Dev Biol 17:433-442

Kline DL (2006) Traps and trapping techniques for adult mosquito control. J Am Mosq Control Assoc 22:490-496

Kline D (2007) Semiochemicals, traps/targets and mass trapping technology for mosquito management. J Am Mosq Control Assoc 23(2):241-251

Kline D, Lemire G (1998) Evaluation of attractant baited traps/targets for mosquito management on Key Island, Florida, USA. J Vect Ecol 23:171-185

Kły’s M, Malejky N, Nowak-Chmura M (2017) The repellent effect of plants and their active substances against the beetle storage pests. J Stored Prod 74:66-77

Landolt PJ, Phillips TW (1997) Host plant influences on sex pheromone behavior of phytophagous insects. Annu Rev Entomol 42:371-391

Leal WS (2013) Odorant reception in insects: roles of receptors, binding proteins, and degrading enzymes. Annu Rev Entomol 58:373-391

Leal WS (2014) The enigmatic reception of DEET-the gold standard of insect repellents. Curr Opin Insect Sci 6:93-98

Liberzon A, Harrington K, Daniel N et al (2018) Moth-inspired navigation algorithm in a turbulent odor plume from a pulsating source. PLoS ONE 10:137

Logan J, Birkett M (2007) Semiochemicals for biting fly control: their identification and exploitation. Pest Manag Sci 63:647-657

Logan JG, Cook JI, Mordue J, Kline D (2010) Understanding and exploiting olfaction for the surveillance and control of Culicoides biting midges. Ecol Control Vector-borne Dis 2:217-246

Machekposhti SA, Mohaved S, Narayan RJ (2019) Inkjet dispensing technologies: recent advances for novel drug discovery. Expert Opin Drug Discov 14(2):101-113

Maia MF, Tenywa FC, Nelson $\mathrm{H}$ et al (2018) Attractive toxic sugar baits for controlling mosquitoes: a qualitative study in Bagamoyo, Tanzania. Malar J 17(22):1-6

Maksimovic S, Tadic V, Skala D, Zizovic I (2017) Separation of phytochemicals from Helichrysum italicum: an analysis of different isolation techniques and biological activity of prepared extracts. Phytochemistry 138:9-28

Mcleod G, Gries R, Von Reuß SH et al (2005) The pathogen causing Dutch elm disease makes host trees attract insect vectors. Proc $\mathrm{R}$ Soc Biol. https://doi.org/10.1098/3202

Menger, DJ, Omusula P, Wouters K et al (2016) Eave screening and push-pull tactics to reduce house entry by vectors of malaria. Am J Trop Med Hyg

Miller JR, Gut LJ (2015) Mating disruption for the 21st century: matching technology with mechanism. Environ Entomol 44:427-453

Mmbando SA, Batista EPA, Kilalangongono M et al (2019) Evaluation of a push-pull system consisting of transfuthrin-treated eave ribbons and odor-baited traps for control of indoor and outdoorbiting malaria vectors. Malar J 18:87

Mota T, Vitta ACR, Lorenzo-Figueiras AN, Barezani CP, Zani CL, Lazzari CR, Diotaiuti L, Jeffares L, Bohman B, Lorenzo MG (2014) A multi-species bait for Chagas disease vectors. PLoS Negl Trop Dis 8:e2677 
Mukabana WR, Olanga EA, Knols BGJ (2010) Host-seeking behavior of Afrotropical anophelines: field and semi-field studies. Ecol Control Vector-borne Dis 2:181-202

Murlis J, Elkinton S, Cardé RT (1992) Odor plumes and how insects use them. Annu Rev Entomol 37:505-532

Mweresa CK, Mukabana WR, Omusula P et al (2014a) Evaluation of textile substrates for dispensing synthetic attractants for malaria mosquitoes. Parasit Vectors 7:376

Mweresa CK, Omusula P, Otieno B et al (2014b) Molasses as a source of carbon dioxide for attracting the malaria mosquito Anopheles gambiae and Anopheles funestus. Malar J 13:160

Mweresa CK, Omusula P, Otieno B et al (2015) Understanding the long-lasting attraction of malaria mosquitoes to odor baits. PLoS ONE 10(3): 0121533

Mweresa CK, Mukabana WR, Otieno B et al (2016) Enhancing attraction of African malaria vectors to a synthetic odor blend. J Chem Ecol 42(6):508-516

Namiki S, Kanzaki R (2016) The neurobiological basis of orientation in insects: insights from the silkmoth mating dance. Curr Opin Insect Sci 15:16-26

Navarro-Silva MA, Marques FA, Duque LJE (2009) Semiochemicals that mediate the oviposition of mosquitoes: a possible sustainable tool 1. Rev Bras Entomol 53(1):1-6

Nordlund DA, Lewis WJ (1976) Terminology of chemical releasing stimuli in intraspecific and interspecific interactions. J Chem Ecol 2:211-220

Nyasembe VO, Tchouassi DP, Pirk CW, Sole CL, Torto B (2019) Host plant forensics and olfactory-based detection in Afro-tropical mosquito disease vectors. PLoS Negl Trop Dis 12(2):e0006185

Ogden NH (2017) Climate change and vector-borne diseases of public health significance. FEMS Microbiol Lett 19(16):364

Onah IE, Adesina FP, Uweh PO, Anumba JU (2017) Challenges of malaria elimination in Nigeria; A review. Int $\mathrm{J}$ Infect Dis 2(4):79-85

Ong S, Jaal Z (2015) Investigation of mosquito oviposition pheromone as lethal lure for the control of Aedes aegypti (L.) (Diptera: Culicidae). Parasit Vectors 8:28

Pelletier J, Hughes DT, Luetje CW, Leal WS (2010) An odorant receptor from the Southern House mosquito: Culex pipiens quinquefasciatus sensitive to oviposition attractants. PLoS ONE 5:e10090

Pocsfalvi G, Stanly C, Fiume I, Vékey K (2016) Chromatography and its hyphenation to mass spectrometry for extracellular vesicle analysis. J Chromatogr 1439:26-41

Qiu YT, Smallegange RC, Hoppe I et al (2004) Behavioral and electrophysiological responses of the malaria mosquito Anopheles gambiae Giles sensu stricto (Diptera: Culicidae) to human skin emanations. Med Vet Entomol 18:429-438

Ray A (2016) Reception of odors and repellents in mosquitoes. Curr Opin Neurobiol 34:158-164

Reisenman CE, Lei H, Guerenstein PG (2016) Neuroethology of olfactory-guided behavior and its potential application in the control of harmful insects. Front Physiol 7:271

Riffell JLH, Christensen TA, Hildebrand J (2009) Characterization and coding of behaviorally significant odor mixtures. Curr Biol 19:335-340

Ryelandt J, Noireau F, Lazzari CR (2011) A multimodal bait for trapping blood-sucking arthropods. Acta Trop 117:131-136

Sánchez-Gracia A, Vieira FG, Rozas J (2009) Molecular evolution of the major chemosensory gene families in insects. Heredity 103:208-216
Smallegange RC, Takken W (2010) Host-seeking behavior of mosquitoes: responses to olfactory stimuli in the laboratory. Ecol Control Vector-borne Dis 2:143-180

Smallegange RC, Qiu TY, van Loon JJA, Takken W (2005) Synergism between ammonia, lactic acid and carboxylic acids as kairomones in the host seeking behavior of the malaria mosquito Anopheles gambiae sensu stricto (Diptera: Culicidae). Chem Senses 30:145-152

Spitzen J, Spoor CW, Grieco F et al (2013) A 3D analysis of flight behavior of Anopheles gambiae sensu stricto malaria mosquitoes in response to human odor and heat. PLoS ONE 8(5):e62995

Sternberg ED, Thomas MB (2018) Insights from agriculture for the management of insecticide resistance in disease vectors. Evol Appl 11(4):404-414

Stökl J, Steiger S (2017) Evolutionary origin of insect pheromones. Curr Opin Insect Sci 24:36-44

Sumaye RD, Lwetoijera DW, Madumla EP, Okumu FO (2012) A geographical location model for targeted implementation of lureand-kill strategies against disease-transmitting mosquitoes in rural areas. MWJ 3:1

Syed Z, Pelletier J, Flounders E, Chitolina RF, Leal WS (2011) Generic insect repellent detector from the fruit fly Drosophila melanogaster. PLoS ONE 6:e17705

Takken W, Verhulst NO (2017) Chemical signaling in mosquito-host interactions: the role of human skin microbiota. Curr Opin Insect Sci 20:68-74

Torr SJ, Hall DR, Phelps RJ, Vale GA (1997) Methods for dispensing odor attractants for tsetse flies (Diptera: Glossinidae). Bull Entomol Res 87:299-311

Tsizin S, Bokka R, Keshet U et al (2017) Comparison of electrospray LC-MS, LC-MS with cold EI and GC-MS with cold EI for sample identification. Int J Mass Spectrom 422:119-125

Vale GA, Torr SJ (2004) Development of bait technology to control tsetse. In: Maudlin I, Holmes PH, Miles MA (eds) The trypanosomiases. CABI, Wallingford, pp 509-523

Valenzuela JG, Aksoy S (2018) Impact of vector biology research on old and emerging neglected tropical diseases. PLoS Negl Trop Dis 12(5): $\mathrm{e} 0006365$

Wang JW, Wong AM, Flores J, Vosshall LB, Axel R (2003) Twophoton calcium imaging reveals an odor-evoked map of activity in the fly brain. Cell 112:271-282

Watentena A, Okoye CI (2019) The untapped potential of mosquito lures for malaria vector surveillance and mass trapping of mosquitoes: a review. Int J Mosq Res 6(1):132-137

WHO (2018) World malaria report. World Health Organization, Geneva, p 2018

Xu P, Choo YM, De La Rosa A, Leal WS (2014) Mosquito odorant receptor for DEET and methyl jasmonate. Proc Natl Acad Sci 111:16592-16597

Yang Y, Li W, Tao J, Zong S (2019) Antennal transcriptome analyses and olfactory protein identification in an important wood-boring moth pest, Streltzoviella insularis (Lepidoptera: Cossidae). Sci Rep 9:17951

Yew JY, Chung H (2015) Insect pheromones: an overview of function, form, and discovery. Prog Lipid Res 59:88-105

Zwiebel LJ, Takken W (2011) Olfactory regulation of mosquito-host interactions. Insect Biochem Mol Biol 34(7):645-652 